\title{
Nanostructured Polylactic Acid/Candeia Essential Oil Mats Obtained by Electrospinning
}

\author{
Cláudia L. S. de Oliveira Mori, ${ }^{1}$ Nathália Almeida dos Passos, ${ }^{2}$ Juliano Elvis Oliveira, \\ Thiza Falqueto Altoé, ${ }^{1}$ Fábio Akira Mori, ${ }^{1}$ Luiz Henrique Capparelli Mattoso, ${ }^{4}$ \\ José Roberto Scolforo, ${ }^{1}$ and Gustavo Henrique Denzin Tonoli ${ }^{1}$ \\ ${ }^{1}$ DCF, Universidade Federal de Lavras, P.O. Box 3037, 37200-000 Lavras, MG, Brazil \\ ${ }^{2}$ DCA, Universidade Federal de Lavras, P.O. Box 3037, 37200-000 Lavras, MG, Brazil \\ ${ }^{3}$ DEG, Universidade Federal de Lavras, P.O. Box 3037, 37200-000 Lavras, MG, Brazil \\ ${ }^{4}$ Laboratório Nacional de Nanotecnologia para o Agronegócio (LNNA), Embrapa Instrumentação (CNPDIA), P.O. Box 741, \\ 13560-970 São Carlos, SP, Brazil
}

Correspondence should be addressed to Gustavo Henrique Denzin Tonoli; gustavotonoli@dcf.ufla.br

Received 9 September 2014; Revised 12 December 2014; Accepted 23 December 2014

Academic Editor: Nay Ming Huang

Copyright ( 2015 Cláudia L. S. de Oliveira Mori et al. This is an open access article distributed under the Creative Commons Attribution License, which permits unrestricted use, distribution, and reproduction in any medium, provided the original work is properly cited.

\begin{abstract}
This work aims to evaluate the effect of inclusion of different contents of candeia (Eremanthus erythropappus) essential oil (whose alpha-bisabolol is the main terpene) on the properties of polylactic acid (PLA) nanostructured mats and their relationship with fiber morphology and structure. The interaction occurring between the PLA and the candeia essential oil was confirmed by thermal and microscopy analysis. Addition of candeia essential oil increased nanofiber diameter and decreased the glass transition and melting temperatures of the nanofibers, suggesting lower energy input for processing. Scanning electron microscopy (SEM) images provided evidence of a homogeneous structure for the nanostructured mats. X-ray diffraction did not show differences in the crystallization of the nanofibers. This ongoing research confirms the possibility of incorporation of candeia essential oil in the production of nanofibers that will be studied for multipurpose applications.
\end{abstract}

\section{Introduction}

Candeia (Eremanthus erythropappus) is a forest species whose wood is popularly used as fence post, due to its high natural durability, and currently is the raw material for production of the essential oil, whose main terpene is the alpha-bisabolol, which confers antibacterial properties that are required in the manufacture of pharmaceuticals, fragrances, and cosmetics [1-4]. The higher incidence of this species in the state of Minas Gerais, Brazil, is predominantly in mountainous locations, rocky and poor soil conditions, which are not obstacles to its development. It is very common to find large candeia forests in places where it would be difficult to develop other arboreal species or agricultural crops [5]. Because of its economic importance, the species has been extensively explored in Minas Gerais, which has been causing a strong reduction of its natural occurrence.
Nanostructured materials obtained from renewable resources have been used for healthcare, production, and processing of food [6], agriculture [7], environmental protection [8], and forestry [9]. The application of nanomaterials across various sectors led to both environmental and economic benefits, including enhanced product quality and more sustainable technologies [8].

A fibrillar or nanofibrillar pattern leads to the possibility of tailoring a wide variety of network-like structures with small pore size (compared to commercial nonwoven fabrics in macroscale). The small fiber diameter and large aspect ratio lead to exceptionally high surface to volume (mass) ratio, which makes the electrospun nanofibers desirable for several applications. Nanofibers obtained from biopolymers are of particular interest for potential applications in medicine, drug delivery, and agriculture $[10,11]$. Biomedical applications of such nonwoven nanofibers comprise wound 
dressing and release of drugs like antibiotics and antiinflammatory [12]. Applications of nanofibers in agriculture could include water treatment [13], the estrous control of livestock animals [14], and crop protection [15]. The actual stage of several technologies requires the development of entirely new approaches for the construction of two- and three-dimensional nanoarchitectures [15]. In many cases, these nanostructures can be obtained by electrospinning [16].

The electrospinning is a simple method that uses electrical forces for obtaining polymer fibers with nanometer scale diameters, leading to high specific surface area and highly porous structures for myriad applications [17]. This method permits obtaining nanofibers straightforwardly, continuously, and cost-effectively [18]. Electrospinning is based on the application of a high voltage across a conductive needle attached to a syringe containing the polymer solution and a conductive collector. The majority of scientific papers related to electrospinning of biodegradable polymers have been focused on synthetic materials, mostly on polylactic acid, polyglycolic acid, and polycaprolactone and their copolymers [19]. In comparison with synthetic counterparts, biopolymers generally present improved biocompatibility and are ecofriendly [20-22].

The PLA is an aliphatic polyester of high molecular weight, which can be achieved by direct polycondensation of lactic acid as the opening polymerization of the cyclic dimer of lactic acid. These methods allow obtaining polymers of high molar mass. The lactic acid monomers used to produce PLA are obtained from the fermentation of wheat, corn, sugarcane, or potato [23]. The poly(L-lactic acid) and poly(L-lactide) have the same structural formula and these two distinct names refer exclusively to a monomer used in the synthesis and may be abbreviated by the acronym PLA [24]. PLA has high mechanical performances when compared to polyethylene, polypropylene, and polystyrene and is hydrolysable in the presence of water, yielding oligomers and monomers with low molecular weight. Besides, PLA can be produced at costs comparable to those of polymers derived from petroleum [25-27]. According to Oliveira et al. [28], blends with other polymers such as polycaprolactone or polyetherurethane have been used to improve the flexibility of the PLA with low molecular weight plasticizers such as citrate esters, polyethylene glycol, polypropylene glycol, and lactic acid oligomer. However, the use of candeia essential oil as a functional addition in the processing of PLA nanostructured mats was not reported in the literature. Then, the objective of this study was to investigate the effect of adding candeia (Eremanthus erythropappus) essential oil at different concentrations $(5,10$, and $15 \%$ by mass) on the properties of nanostructured PLA mats obtained by electrospinning.

\section{Materials and Methods}

2.1. Materials. Polylactic acid (PLA) was obtained from Nature Works, 4046D. The HFIP (1,1,1,3,3,3-hexafluoro-2propanol) was purchased from Chemical Synth (São Paulo, Brazil) and used as a solvent.

The candeia (Eremanthus erythropappus) wood (with 9 years) used for extraction of the essential oil was crop from
TABLE 1: Blend design for production of the nanostructured mats.

\begin{tabular}{lcc}
\hline Sample & $\begin{array}{c}\text { Blend ratio (PLA : candeia } \\
\text { essential oil) }\end{array}$ & $\begin{array}{c}\text { Mass fraction } \\
\text { of PLA (wt\%) }\end{array}$ \\
\hline PLA (neat) & $1.00: 0.00$ & 100 \\
PLAO1 & $0.95: 0.05$ & 95 \\
PLAO2 & $0.90: 0.10$ & 90 \\
PLAO3 & $0.85: 0.15$ & 85 \\
\hline
\end{tabular}

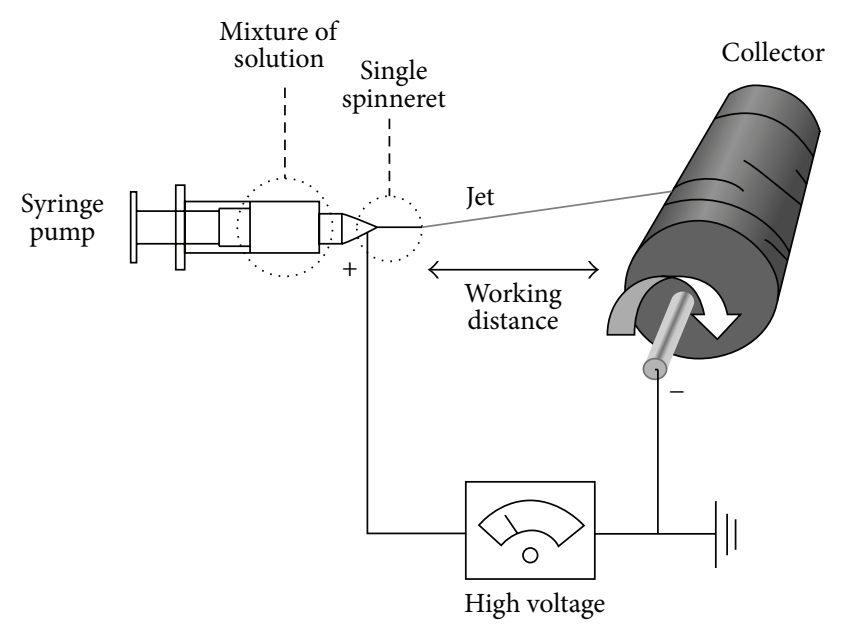

FIGURE 1: Schematic diagram of the electrospinning setup.

an artificial plantation located in Carrancas, MG state, Brazil, under the coordinates $21^{\circ} 33^{\prime} 00.21^{\prime \prime} \mathrm{S}$ and $44^{\circ} 42^{\prime} 43.43^{\prime \prime} \mathrm{W}$ and between 896 and $1590 \mathrm{~m}$ high, tropical altitude climate, Köppen Cwa, with moderate temperatures, hot and rainy summer, with an average annual temperature of $14.8^{\circ} \mathrm{C}$ and mean annual precipitation of $1470 \mathrm{~mm}$. Candeia essential oil was obtained by hydrodistillation of candeia wood chips using a modified Clevenger apparatus for $4 \mathrm{~h}$. Chemical composition of the essential oil was performed by gas chromatography coupled to mass spectrometry (GC-MS). The chromatograph used was the model equipped with mass selective detector model 7643 autosampler and MSD 5975C Agilent 7890A.

2.2. Production of the Nanostructured Mats. Four formulations were tested, as presented in Table 1. Definition of the essential oil concentrations was based on previous work [29]. The HFIP solvent was added to each assay tube to take the final concentration of biopolymer to $20 \%$ by weight. The formulations were prepared using a polymer (PLA) concentration of $20 \%$ (by mass). The formulations were rigorously stirred for several hours (up to $24 \mathrm{~h}$ ) to ensure the complete dissolution of the constituents. The polymer solutions were spun into nanofibers by electrospinning at room temperature $\left(\sim 24^{\circ} \mathrm{C}\right)$ and around $65 \%$ relative humidity $(\mathrm{RH})$ and following the procedures described in Oliveira et al. [30] and Mori et al. [11]. A syringe pump (KD scientific, model $781100)$ was used to feed the polymer solution $(20 \mu \mathrm{L} / \mathrm{min})$ through a needle (Figure 1). High voltage was applied between the needle and the collector, at a constant value $(20 \mathrm{kV})$. 
The electrospinning parameters were kept constant for all experiments, and the nanofibers were collected on a rotating drum with a working distance of $12 \mathrm{~cm}$. The nonwoven nanofiber mats of each formulation were stored in sealed plastic bags in a desiccator until the characterization tests.

2.3. Scanning Electron Microscopy (SEM). The morphology of the electrospun nanofibers was analyzed using scanning electron microscopy (SEM, Zeiss, model DSM960). Samples were prepared by cutting the nonwoven nanofiber mats with a razor blade and mounting them on aluminum stubs using double-side adhesive tape. Samples were then gold sputtering coated (Balzers model SCD 050, Balzers Union AG, Balzers). The nanofiber diameters were measured with the aid of image analyses software (Image J, National Institutes of Health). The average nanofiber diameter and diameter distribution were determined from approximately 100 random measurements using representative micrographs.

2.4. Thermal Analysis. Differential scanning calorimetry (DSC, TA Instruments Calorimetric Analyzer, Q100 model) was performed under nitrogen atmosphere, at a flow rate of $20 \mathrm{~mL} / \mathrm{min}$ and with a heating rate of $10^{\circ} \mathrm{C} / \mathrm{min}$. Samples were sealed in aluminum pans and heated from $-85^{\circ} \mathrm{C}$ to $230^{\circ} \mathrm{C}$ for all nanofibers samples. The glass transition temperature ( $\mathrm{Tg}$ ) was obtained by analysis of the second heating cycle.

2.5. X-Ray Diffraction (XRD). XRD patterns of the electrospun nanostructured mats were recorded using a Shimadzu (XRD-6000) X-ray diffractometer. Scans were carried out from $3^{\circ}$ to $35^{\circ}(2 \theta)$ at a scan rate of $5 / \mathrm{min}$ using Ni filtered $\mathrm{Cu}-\mathrm{K} \alpha$ radiation (wavelength of $0.154 \mathrm{~nm}$ ) at $50 \mathrm{kV}$ and $20 \mathrm{~mA}$.n. The full-width at half-maximum height (FWHM) of the diffraction peaks was calculated by fitting the $\mathrm{X}$ ray diffraction patterns with a Gaussian-Lorentzian function (Origin 7.5 software, Origin Lab, USA). The $d$-spacing for a given scattering angle, $2 \theta$, was calculated by application of Bragg equation:

$$
d=\frac{\lambda}{2 \sin \theta}
$$

where $\lambda$ is the wavelength of the $\mathrm{Cu}-\mathrm{K} \alpha$ radiation.

The crystallite size, $D$, was estimated by calculating the broadening of the diffraction peaks according to Scherrer equation:

$$
D=\frac{k \lambda}{\beta \cos \theta},
$$

where $k$ is the Scherrer constant that is dependent upon the lattice direction and crystallite morphology and $\beta$ is the fullwidth at half-maximum height given in radians. A $k$ value of 0.9 was used in this study, which is based on values found in the literature for crystals of biopolymers [31, 32].

\section{Results and Discussion}

3.1. Characterization of the Candeia Essential Oil. The average yield of essential oil was $0.76 \%$ in relation to the dry mass
TABLE 2: Average diameter and standard deviation of the electrospun nanofibers and bead content in the nanofiber mats.

\begin{tabular}{lcc}
\hline Electrospun nanofibers & $\begin{array}{c}\text { Diameter } \\
(\mathrm{nm})\end{array}$ & $\begin{array}{c}\text { Bead content } \\
\left(\mathrm{bead} / \mu \mathrm{m}^{2}\right)\end{array}$ \\
\hline PLA (neat) & $107 \pm 42$ & 0.06 \\
PLAO1 & $123 \pm 47$ & 0.02 \\
PLAO2 & $147 \pm 51$ & 0.01 \\
PLAO3 & $152 \pm 53$ & 0.01 \\
\hline
\end{tabular}

PLAO1: 5\% of candeia essential oil and 95\% of PLA; PLAO2: 10\% of candeia essential oil and 90\% of PLA; PLAO3: 15\% of candeia essential oil and $85 \%$ of PLA.

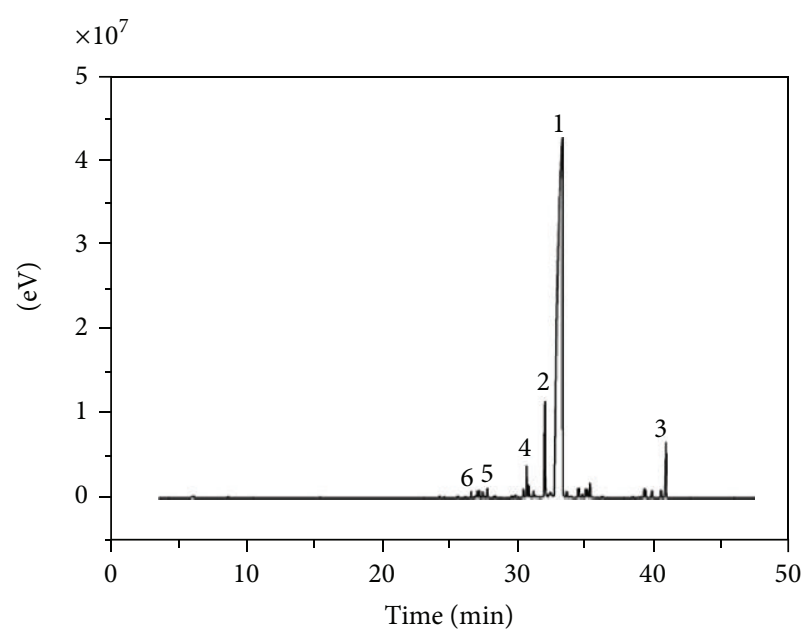

FIGURE 2: Chromatogram of essential oil of candeia wood: $1=$ alphabisabolol; 2 = alpha-bisabolol oxide; 3 = eremanthin; 4 = spathulenol; $5=\beta$-selinene; and $6=\delta$-selinene.

of wood, which leads to around $130 \mathrm{Kg}$ per hectare of candeia trees. According to chromatography results, the major components found in the candeia essential oil were alphabisabolol (89.8\%), alpha-bisabolol oxide (3.9\%), eremanthin (1.6\%), spathulenol (0.9\%), $\beta$-selinene $(0.2 \%)$, and $\delta$-selinene $(0.2 \%)$ (Figure 2). These six chemical components represent around $97 \%$ of the candeia essential oil.

3.2. Scanning Electron Microscopy (SEM). SEM images (Figure 3) confirmed the interaction between the candeia essential oil and PLA, because no delamination or phase separation was observed in the structure of an individual nanofiber. This interaction occurred between the candeia essential oil and PLA through the hydroxyls in the lactic acid and terpenes and sesquiterpene alcohols (components of the candeia essential oil). The nanofibers are relatively uniform in thickness, randomized and distributed forming a nonwoven web, with homogeneous morphology of this nanostructured mats and absence of agglomerates.

Table 2 presents the average diameters and the beads content formed during electrospinning, while Figure 4 depicts the diameter distribution of the electrospun nanofibers of the different formulations. The addition of candeia essential oil seems to decrease the formation of beads. The diameter 
TABLE 3: Thermal properties of the different formulations of the nanostructured mats of PLA/candeia essential oil.

\begin{tabular}{|c|c|c|c|c|c|c|c|}
\hline Electrospun fibers & $T_{g}\left({ }^{\circ} \mathrm{C}\right)$ & $T_{m 1}\left({ }^{\circ} \mathrm{C}\right)$ & $\Delta H_{m 1}(\mathrm{~J} / \mathrm{g})$ & $T_{c}\left({ }^{\circ} \mathrm{C}\right)$ & $\Delta H_{c}(\mathrm{~J} / \mathrm{g})$ & $T_{m 2}\left({ }^{\circ} \mathrm{C}\right)$ & $\Delta H_{m 2}(\mathrm{~J} / \mathrm{g})$ \\
\hline PLA (neat) & 60 & 150 & 22 & 119 & 8 & 153 & 0.4 \\
\hline PLAO1 & 49 & 147 & 30 & $80 / 122$ & $10 / 6$ & 147 & 8 \\
\hline PLAO2 & 46 & 146 & 28 & $85 / 124$ & $18 / 2$ & 146 & 3 \\
\hline PLAO3 & 42 & 145 & 30 & $78 / 121$ & $13 / 3$ & 145 & 5 \\
\hline
\end{tabular}

$T_{g}=$ glass transition temperature; $T_{m 1}=$ melting temperature at the first cycle; $\Delta H_{m 1}=$ melting enthalpy at the first cycle; $T_{c}\left({ }^{\circ} \mathrm{C}\right)=$ crystallization temperature at the first and second cycles (separated by /); $\Delta H_{c}=$ crystallization enthalpy at the first and second cycles (separated by /); $T_{m 2}=$ melting temperature at the second cycle; $\Delta H_{m 2}(\mathrm{~J} / \mathrm{g})=$ melting enthalpy at the second cycle; PLAO1 $=5 \%$ of candeia essential oil and $95 \%$ of PLA; PLAO2 = $10 \%$ of candeia essential oil and $90 \%$ of PLA; PLAO3 $=15 \%$ of candeia essential oil and $85 \%$ of PLA.

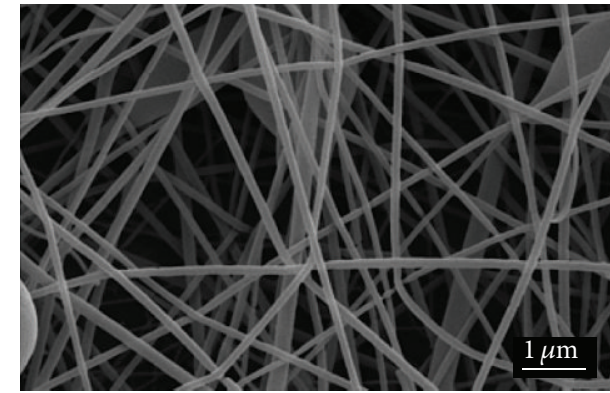

(a)

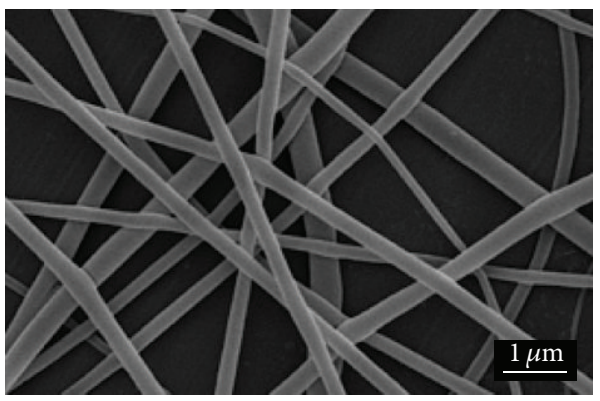

(c)

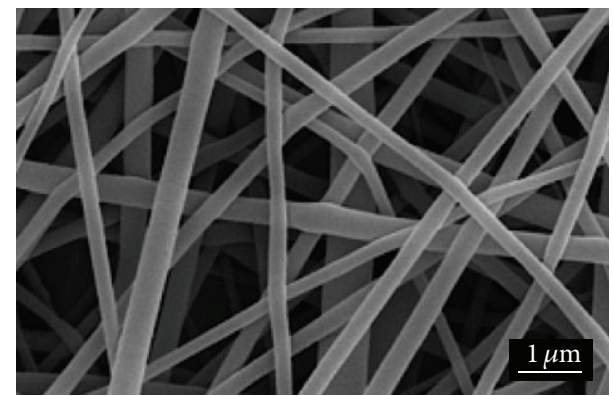

(b)

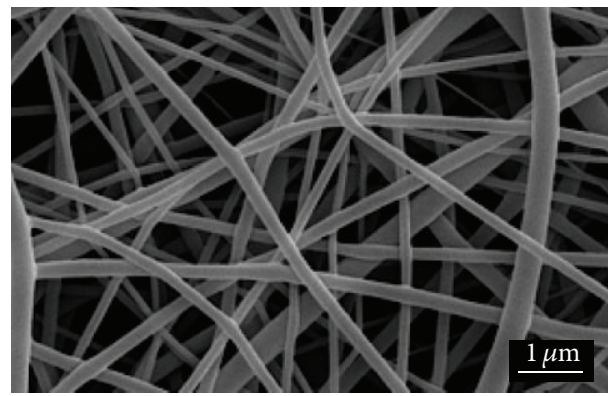

(d)

FIGURE 3: Scanning electron microscopy (SEM) images of the nanostructured mats: (a) PLA (neat PLA); (b) PLAO1 (5\% of candeia essential oil and $95 \%$ of PLA); (c) PLAO2 (10\% of candeia essential oil and $90 \%$ of PLA); and (d) PLAO3 (15\% of candeia essential oil and $85 \%$ of PLA).

of the electrospun nanofibers ranges from 10 to $360 \mathrm{~nm}$ (Figure 4) and the length exceeds $10 \mu \mathrm{m}$. The dimensions of these micro/nanofibrils are similar to that obtained via electrospinning by del Valle et al. [33]. About 53\% of the nanofibers obtained with pure PLA are lower than $100 \mathrm{~nm}$ in diameter, while nanomats obtained with addition of 5\% (PLAO1), 10\% (PLAO2), and 15\% (PLAO3) of candeia essential oil presented around $42 \%, 30 \%$, and $25 \%$ of the nanofibers with diameters lower than $100 \mathrm{~nm}$, respectively. The increase in the concentration of candeia essential oil led to increase of the diameter of the nanofibers. This may be because of the electric conductivity of the solution that decreased with the addition of essential oil and resulted in increase of the nanofibers diameter. Low conductivity of the solution results in insufficient elongation of the jet by the electric forces and leads to production of large nanofiber diameters [34, 35]. Diameter of the nanofibers may also be affected by the solution viscosity that can be explained in terms of the interaction forces taking place between the essential oil and PLA. Depending on the type and intensity of these interactions, rheology of the polymer solutions may change [14]. Normally, higher viscosities lead to large fiber diameters $[36,37]$. The different structural arrangements of the polymer chains in the nanofibers ultimately may also affect the releasing of the essential oil [38]. In the present case, the increase of the essential oil led to a small decrease of the viscosity, which probably did not affect the diameter of the nanofibers.

3.3. Thermal Analysis. The addition of candeia essential oil decreased the glass transition temperature of the nanofibers, suggesting a plasticizing effect of the essential oil on the PLA (Figure 5). The melting temperature is related to the crystallinity of the studied nanofibers. It was observed that the increase of the essential oil concentration decreased the melting temperature of the nanofibers (Figure 5, Table 3) suggesting lower energy input for processing. The increase in the melting enthalpy with the presence of essential oil can also 


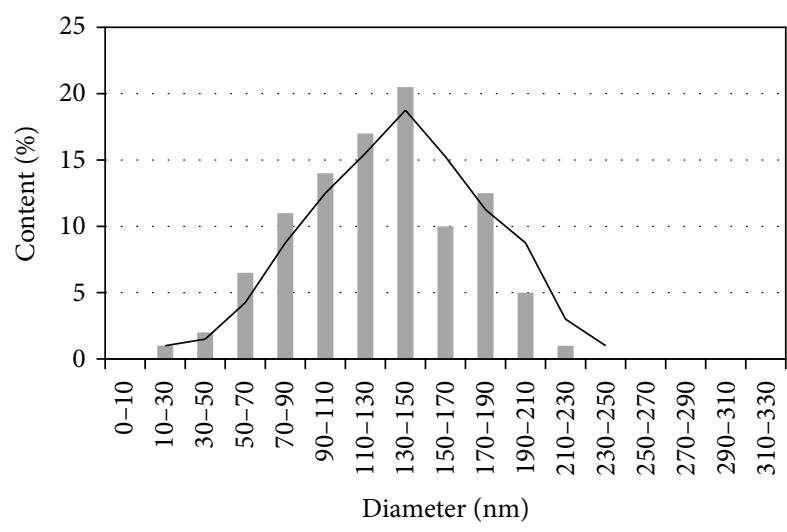

(a)

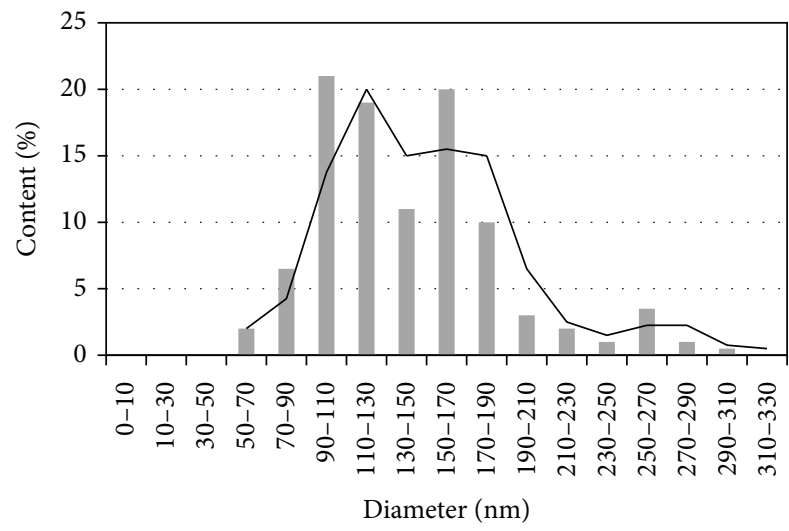

(c)

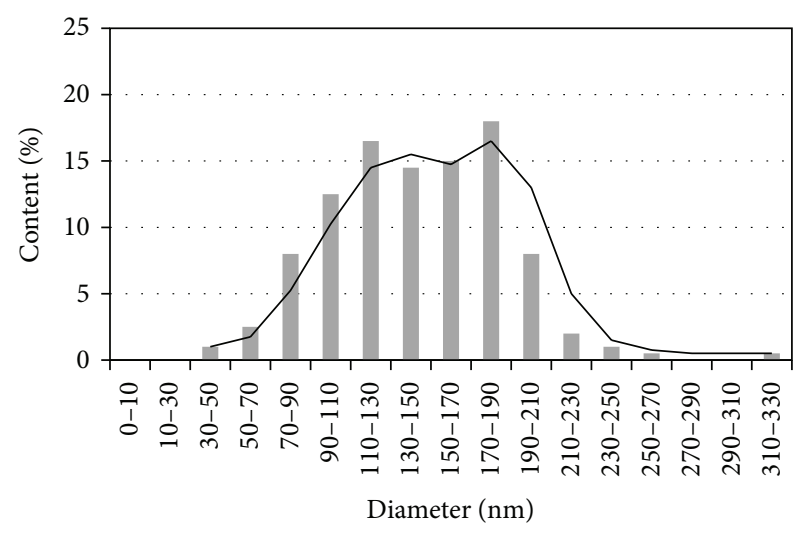

(b)

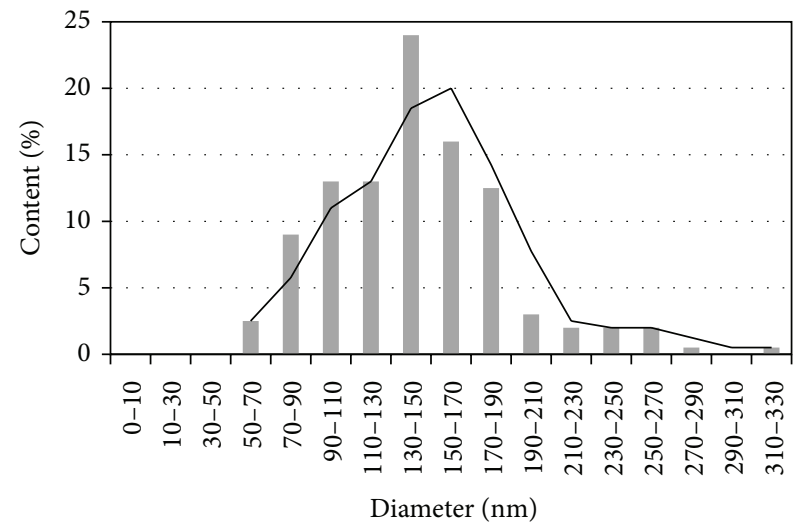

(d)

FIGURE 4: Diameter distribution histograms of the nanofibers: (a) PLA (neat PLA); (b) PLAO1 (5\% of candeia essential oil and 95\% of PLA); (c) PLAO2 (10\% of candeia essential oil and 90\% of PLA); and (d) PLAO3 (15\% of candeia essential oil and $85 \%$ of PLA).

be associated with the plasticizing effects previously mentioned. Thermal degradation of the polymer is result of the molecular degradation with heating. At high temperatures the long chain polymers begin to suffer molecular hydrolysis leading to changes of the polymer properties [39]. In other PLA systems, it was possible to detect a more gradual change in the glass behavior, where the existence of two independent (inter- and intraspherulitic) mobile amorphous phases was suggested $[40,41]$. The glass transition dynamics of both amorphous and semicrystalline PLA were also investigated by Mano et al. [42]; and in that case no significant variation of the stiffness index was observed.

Table 3 presents the values of glass transition temperature (Tg), melting temperature (Tm), and crystallization temperature (Tc), which decreased with increasing of the content of candeia essential oil. Balogh et al. [43] also observed this behavior with the inclusion of carvedilol in an amorphous methacrylate terpolymer matrix. The crystallinity of the nanofiber increased with the addition of candeia essential oil, as evidenced by the results of DSC. Choi and Park [44] observed the reduction of the glass transition temperature with the addition of epoxidized soybean oil in poly-3hydroxybutyrate-co-valerate (PHBV) nanofibers.

Nanostructured mats formulated with candeia essential oil presented one crystallization process in the first heating cycle and another one in the second cycle. This phenomenon is not observed for the PLA neat mats. The values of temperature and enthalpy of crystallization for the first and second cycles are separated by slashes (/) in Table 3. We also noted the merge of the PLA in the two heating cycles. The glass transition temperature $(\mathrm{Tg})$ was obtained by analysis of the second heating cycle. Mano et al. [42] concluded that crystallinity in PLA has two main effects on the overall glass transition dynamics: (i) shift of the glass transition temperature to higher values and (ii) broadening of the distribution of relaxation times. The influence of the geometrical confinement on the glass transition behavior may be analyzed under the framework of the Adam and Gibbs theory [45], using the concept of the cooperatively rearranging regions (CRR). They are defined as the smallest regions around a relaxing entity that can undergo a transition to a new configuration state without requiring simultaneous configuration changes outside its boundaries.

3.4. X-Ray Diffraction. Figure 6 depicts the X-ray diffractograms of the nanostructured mats. The interplanar distances were not affected by the presence of candeia essential oil, even in the high concentration (PLAO3), as confirmed by Table 4. Oliveira et al. [46] reported the results of their work to increase the molecular weight of PLA, which leads to 
TABLE 4: Interplanar distances $(d)$ and crystallite diameters $(D)$ of the crystalline parts of the electrospun nanofibers.

\begin{tabular}{lcccccc}
\hline Electrospun fibers & $d_{1}(\AA)$ & $d_{2}(\AA)$ & $d_{3}(\AA)$ & $D_{1}(\mathrm{~nm})$ & $D_{2}(\mathrm{~nm})$ & 6 \\
PLA (neat) & 4 & 2 & 3 & 2 & $D_{3}(\mathrm{~nm})$ \\
PLAO1 & 4 & 2 & 3 & 2 & 6 & 5 \\
PLAO2 & 4 & 2 & 3 & 2 & 6 & 5 \\
PLAO3 & 4 & 2 & 3 & 2 & 6 & 5 \\
\hline
\end{tabular}

Subscripted: peak number: $1\left(14^{\circ}\right), 2\left(17^{\circ}\right)$, and $3\left(25^{\circ}\right)$; PLAO1: 5\% of candeia essential oil and 95\% of PLA; PLAO2: $10 \%$ of candeia essential oil and $90 \%$ of PLA; PLAO3: $15 \%$ of candeia essential oil and $85 \%$ of PLA.

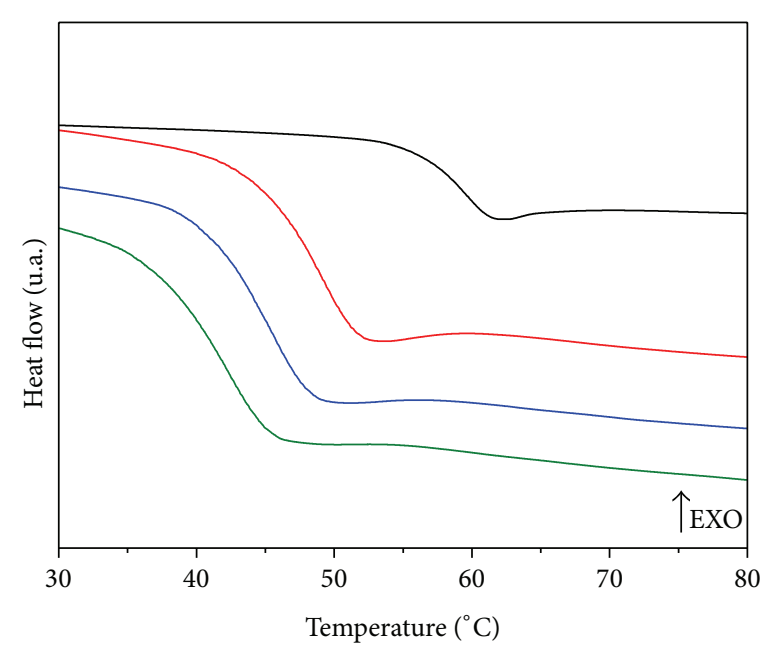

(a)

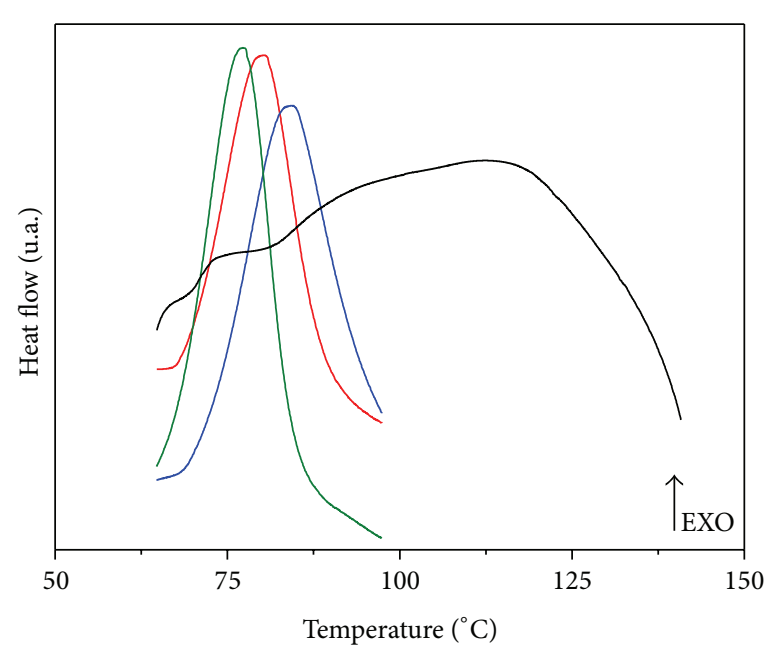

(b)

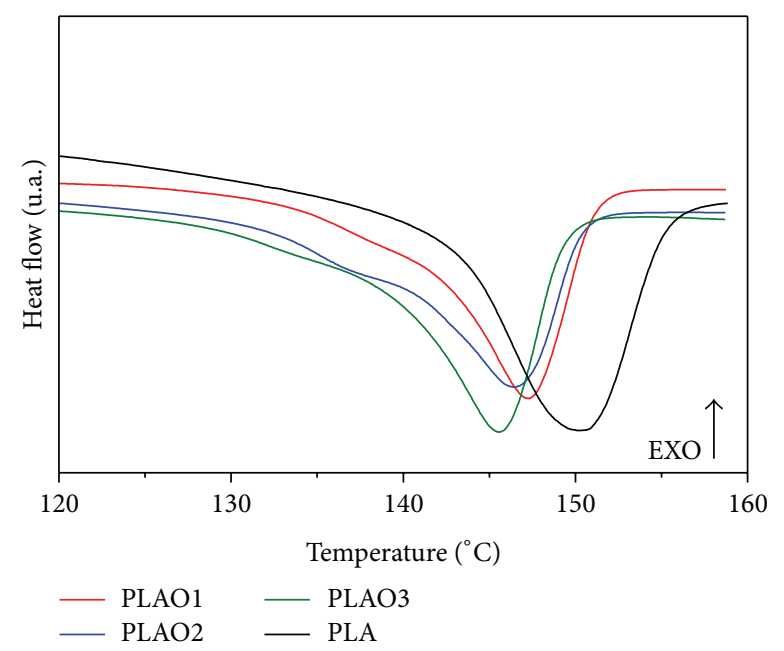

(c)

FIGURE 5: DSC curves showing the effect of candeia essential oil addition on (a) glass transition temperature, (b) cold crystallization, and (c) merging of the electrospun PLA nanofibers. PLAO1: 5\% of candeia essential oil and 95\% of PLA; PLAO2: 10\% of candeia essential oil and 90\% of PLA; PLAO3: $15 \%$ of candeia essential oil and $85 \%$ of PLA.

increased viscosity of the solutions and the average diameter of the fibers obtained. Furthermore, according to those authors, fibers obtained from lower molecular weight PLA have lower crystallinity. These results show that controlling the molecular weight and concentration of polymer in solution can control the morphology of the fibers obtained, as well as their degree of crystallinity.

\section{Conclusion}

The nanofibers produced with polylactic acid (PLA) and candeia (Eremanthus erythropappus) essential oil were successfully obtained by electrospinning. Thermal analysis and morphological characterization of the electrospun nanofibers showed that the interaction between PLA and candeia 


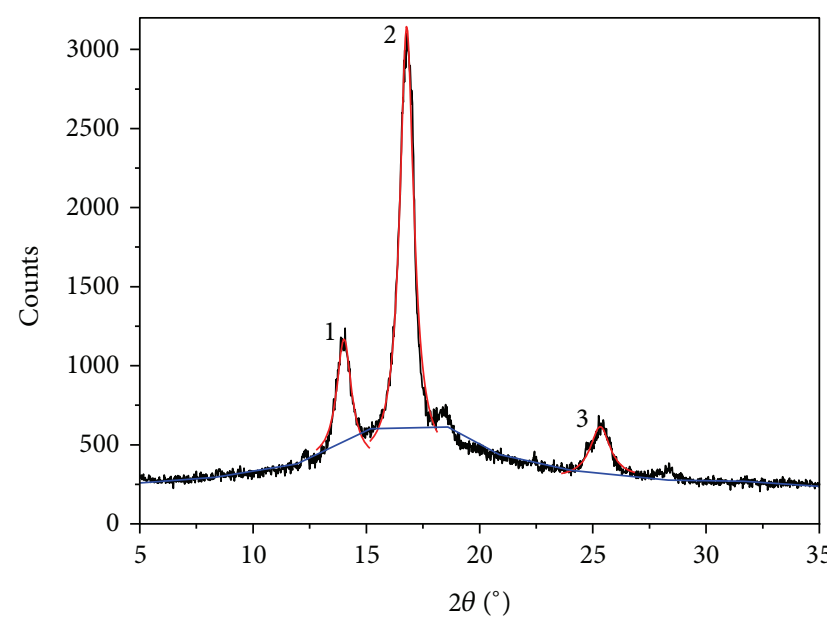

(a)

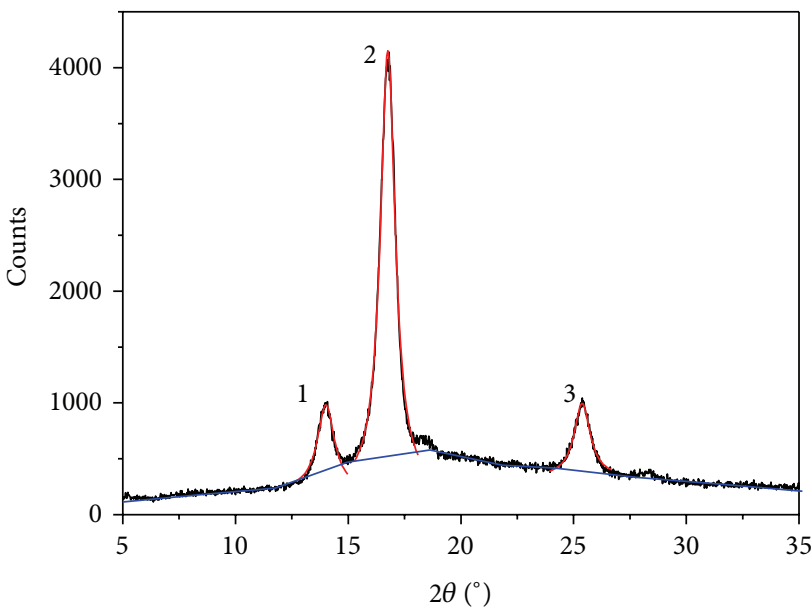

(c)

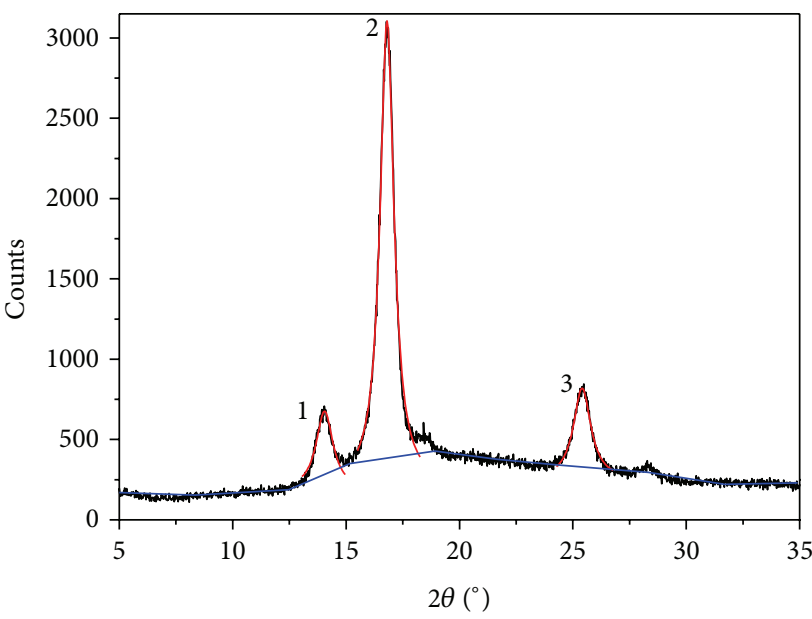

(b)

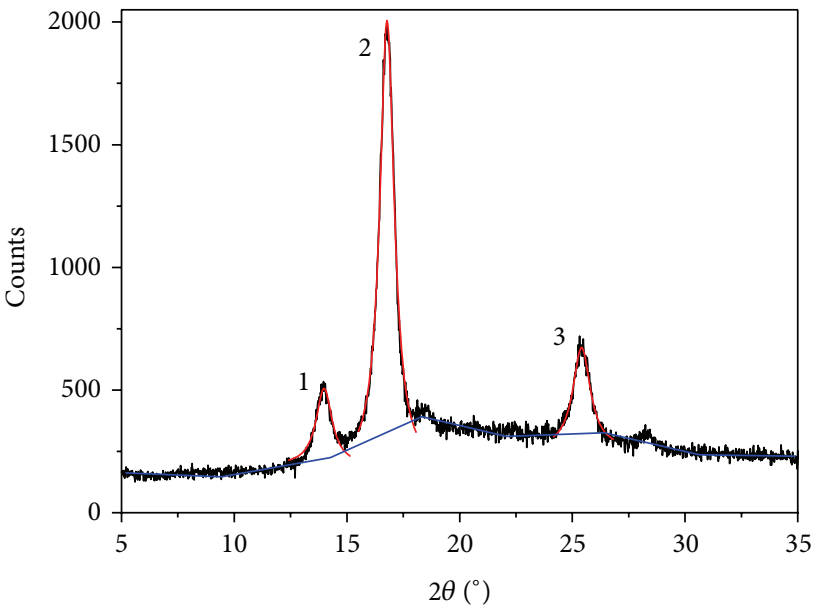

(d)

Figure 6: X-ray diffractograms (XRD) of the nanostructured mats: (a) PLA (neat PLA); (b) PLAO1 (5\% of candeia essential oil and 95\% of PLA); (c) PLAO2 (10\% of candeia essential oil and 90\% of PLA); and (d) PLAO3 (15\% of candeia essential oil and $85 \%$ of PLA).

essential oil occurred. The images obtained by scanning electron microscopy show nanofibers with similar structure and homogeneous morphology in nanostructured nonwoven mats. The addition of essential oil increased the nanofiber diameter and decreased the glass transition and melting temperatures of the nanofibers, showing the plasticizing effect of the essential oil in the PLA matrix. X-ray diffraction did not show differences in the crystallization of the nanofibers. This work confirms the possibility of incorporating the candeia essential oil for producing electrospun nanofibers. The thermal properties of these nanofibers, combined with the chemical activities of the oil and its compatibility with hydrophobic polymeric matrices, open new perspectives for the development of new basis of polymeric materials for various applications, such as antibacterial applications, cosmetics, and controlled release of drugs.

\section{Conflict of Interests}

The authors declare that there is no conflict of interests regarding the publication of this paper.

\section{Acknowledgments}

The authors acknowledge the support of Fundação de Amparo à Pesquisa do Estado de São Paulo (FAPESP), Fundação de Amparo à Pesquisa do Estado de Minas Gerais (FAPEMIG), Coordenação de Aperfeiçoamento de Pessoal de Nível Superior (CAPES), Conselho Nacional de Desenvolvimento Científico e Tecnológico (CNPq), Embrapa Instrumentação, and Brazilian Research Network in Lignocellulosic Composites and Nanocomposites (RELIGAR).

\section{References}

[1] J. F. Cândido, Cultura da candeia (Vanillosmopsis erythropappa Sch. Bip.), UFV, 1991.

[2] P. E. R. Carvalho, Espécies florestais brasileiras: recomendações silviculturais, potencialidades e uso da madeira, EMBRAPACNPF/SPI, 1994.

[3] A. P. P. Galdino, J. O. Brito, R. F. Garcia, and J. R. Scolforo, "Estudo sobre o rendimento e a qualidade do óleo essencial de candeia (Eremanthus ssp) e a influência das diferentes origens 
da sua madeira," Revista Brasileira de Plantas Medicinais, vol. 8, no. 4, pp. 44-46, 2006.

[4] C. L. S. D. O. Mori, J. O. Brito, J. R. S. Scolforo, E. J. Vidal, and L. M. Mendes, "Influence of altitude, age and diameter on yield and alpha-bisabolol content of candeia trees (Eremanthus erythropappus)," Cerne, vol. 15, no. 3, pp. 339-345, 2009.

[5] J. F. M. Pérez, J. R. S. Scolforo, A. D. de Oliveira, J. M. de Mello, L. F. R. Borges, and J. F. Camolesi, "Sistema de manejo para a candeia-eremanthus erythropappus (DC.) MacLeish a opção do sistema de corte seletivo," CERNE, vol. 10, no. 2, pp. 257-273, 2004.

[6] C. Kriegel, A. Arrechi, K. Kit, D. J. McClements, and J. Weiss, "Fabrication, functionalization, and application of electrospun biopolymer nanofibers," Critical Reviews in Food Science and Nutrition, vol. 48, no. 8, pp. 775-797, 2008.

[7] P. Bansal, K. Bubel, S. Agarwal, and A. Greiner, "Water-stable all-biodegradable microparticles in nanofibers by electrospinning of aqueous dispersions for biotechnical plant protection," Biomacromolecules, vol. 13, no. 2, pp. 439-444, 2012.

[8] M. Gavrilescu and Y. Chisti, "Biotechnology-a sustainable alternative for chemical industry," Biotechnology Advances, vol. 23, no. 7-8, pp. 471-499, 2005.

[9] M. Spasova, N. Manolova, M. Naydenov, J. Kuzmanova, and I. Rashkov, "Electrospun biohybrid materials for plant biocontrol containing chitosan and Trichoderma viride spores," Journal of Bioactive and Compatible Polymers, vol. 26, no. 1, pp. 48-55, 2011.

[10] Y. P. Neo, S. Ray, A. J. Easteal, M. G. Nikolaidis, and S. Y. Quek, "Influence of solution and processing parameters towards the fabrication of electrospun zein fibers with submicron diameter," Journal of Food Engineering, vol. 109, no. 4, pp. 645-651, 2012.

[11] C. L. S. O. Mori, N. A. dos Passos, J. E. Oliveira et al., "Electrospinning of zein/tannin bio-nanofibers," Industrial Crops and Products, vol. 52, pp. 298-304, 2014.

[12] D. W.-C. Chen, F.-Y. Lee, J.-Y. Liao, S.-J. Liu, C.-Y. Hsiao, and J.-K. Chen, "Preclinical experiments on the release behavior of biodegradable nanofibrous multipharmaceutical membranes in a model of four-wall intrabony defect," Antimicrobial Agents and Chemotherapy, vol. 57, no. 1, pp. 9-14, 2013.

[13] C. Feng, K. C. Khulbe, T. Matsuura, S. Tabe, and A. F. Ismail, "Preparation and characterization of electro-spun nanofiber membranes and their possible applications in water treatment," Separation and Purification Technology, vol. 102, pp. 118-135, 2013.

[14] J. E. Oliveira, E. S. Medeiros, L. Cardozo et al., "Development of poly(lactic acid) nanostructured membranes for the controlled delivery of progesterone to livestock animals," Materials Science and Engineering C, vol. 33, no. 2, pp. 844-849, 2013.

[15] J. Sun, K. Bubel, F. Chen, T. Kissel, S. Agarwal, and A. Greiner, "Nanofibers by green electrospinning of aqueous suspensions of biodegradable block copolyesters for applications in medicine, pharmacy and agriculture," Macromolecular Rapid Communications, vol. 31, no. 23, pp. 2077-2083, 2010.

[16] C. R. Lowe, "Nanobiotechnology: the fabrication and applications of chemical and biological nanostructures," Current Opinion in Structural Biology, vol. 10, no. 4, pp. 428-434, 2000.

[17] P. Ramesh Kumar, N. Khan, S. Vivekanandhan, N. Satyanarayana, A. K. Mohanty, and M. Misra, "Nanofibers: effective generation by electrospinning and their applications," Journal of Nanoscience and Nanotechnology, vol. 12, no. 1, pp. 1-25, 2012.
[18] D. H. Reneker and I. Chun, "Nanometre diameter fibres of polymer, produced by electrospinning," Nanotechnology, vol. 7, no. 3, pp. 216-223, 1996.

[19] N. Ashammakhi, I. Wimpenny, L. Nikkola, and Y. Yang, "Electrospinning: methods and development of biodegradable nanofibres for drug release," Journal of Biomedical Nanotechnology, vol. 5, no. 1, pp. 1-19, 2009.

[20] R. Shukla and M. Cheryan, "Zein: the industrial protein from corn," Industrial Crops and Products, vol. 13, no. 3, pp. 171-192, 2001.

[21] J. W. Lawton, "Zein: a history of processing and use," Cereal Chemistry, vol. 79, no. 1, pp. 1-18, 2002.

[22] D. S. Cha and M. S. Chinnan, "Biopolymer-based antimicrobial packaging: a review," Critical Reviews in Food Science and Nutrition, vol. 44, no. 4, pp. 223-237, 2004.

[23] Q. Gao, P. Lan, H. Shao, and X. Hu, "Direct synthesis with melt polycondensation and microstructure analysis of poly(L-lactic acid-co-glycolic acid)," Polymer Journal, vol. 34, no. 11, pp. 786$793,2002$.

[24] E. J. Khantzian, "Reflections on group treatments as corrective experiences for addictive vulnerability," International Journal of Group Psychotherapy, vol. 51, no. 1, pp. 11-20, 2001.

[25] I. Grizzi, H. Garreau, S. Li, and M. Vert, "Hydrolytic degradation of devices based on poly(DL-lactic acid) size-dependence," Biomaterials, vol. 16, no. 4, pp. 305-311, 1995.

[26] S. Sinha Ray, P. Maiti, M. Okamoto, K. Yamada, and K. Ueda, "New polylactide/layered silicate nanocomposites. 1. Preparation, characterization, and properties," Macromolecules, vol. 35, no. 8, pp. 3104-3110, 2002.

[27] H. Tsuji, K. Ikarashi, and N. Fukuda, "Poly(L-lactide): XII. Formation, growth, and morphology of crystalline residues as extended-chain crystallites through hydrolysis of poly $(\mathrm{L}-$ lactide) films in phosphate-buffered solution," Polymer Degradation and Stability, vol. 84, no. 3, pp. 515-523, 2004.

[28] J. E. Oliveira, E. A. Moraes, J. M. Marconcini, L. H. C. Mattoso, G. M. Glenn, and E. S. Medeiros, "Properties of poly(lactic acid) and poly(ethylene oxide) solvent polymer mixtures and nanofibers made by solution blow spinning," Journal of Applied Polymer Science, vol. 129, no. 6, pp. 3672-3681, 2013.

[29] M. A. Souza, J. E. Oliveira, E. S. Medeiros, G. M. Glenn, and L. H. C. Mattoso, "Controlled release of linalool using nanofibrous membranes of poly(lactic acid) obtained by electrospinning and solution blow spinning: a comparative study," Journal of Nanoscience and Nanotechnolo, vol. 15, no. 8, pp. 5628-5636, 2015.

[30] J. E. Oliveira, V. P. Scagion, V. Grassi, D. S. Correa, and L. H. C. Mattoso, "Modification of electrospun nylon nanofibers using layer-by-layer films for application in flow injection electronic tongue: detection of paraoxon pesticide in corn crop," Sensors and Actuators B: Chemical, vol. 171-172, pp. 249-255, 2012.

[31] P. Huang, J. X. Zheng, S. Leng et al., "Poly(ethylene oxide) crystal orientation changes in an inverse hexagonal cylindrical phase morphology constructed by a poly(ethylene oxide)block- polystyrene diblock copolymer," Macromolecules, vol. 40, no. 3, pp. 526-534, 2007.

[32] C. Marega, A. Marigo, V. Di Noto, R. Zannetti, A. Martorana, and G. Paganetto, "Structure and crystallization kinetics of poly(L-lactic acid)," Macromolecular Chemistry and Physics, vol. 193, no. 7, pp. 1599-1606, 1992.

[33] L. J. del Valle, A. Díaz, M. Royo, A. Rodríguez-Galán, and J. Puiggalí, "Biodegradable polyesters reinforced with triclosan 
loaded polylactide micro/nanofibers: properties, release and biocompatibility," Express Polymer Letters, vol. 6, no. 4, pp. 266282, 2012.

[34] N. Bhardwaj and S. C. Kundu, "Electrospinning: a fascinating fiber fabrication technique," Biotechnology Advances, vol. 28, no. 3, pp. 325-347, 2010.

[35] C. Yang, X. Wu, Y. Zhao, L. Xu, and S. Wei, "Nanofibrous scaffold prepared by electrospinning of poly(vinyl alcohol)/gelatin aqueous solutions," Journal of Applied Polymer Science, vol. 121, no. 5, pp. 3047-3055, 2011.

[36] N. T. B. Linh, Y. K. Min, H.-Y. Song, and B.-T. Lee, "Fabrication of polyvinyl alcohol/gelatin nanofiber composites and evaluation of their material properties," Journal of Biomedical Materials Research Part B: Applied Biomaterials, vol. 95, no. 1, pp. 184-191, 2010.

[37] D. Yang, Y. Li, and J. Nie, "Preparation of gelatin/PVA nanofibers and their potential application in controlled release of drugs," Carbohydrate Polymers, vol. 69, no. 3, pp. 538-543, 2007.

[38] K. A. Rieger and J. D. Schiffman, "Electrospinning an essential oil: cinnamaldehyde enhances the antimicrobial efficacy of chitosan/poly(ethylene oxide) nanofibers," Carbohydrate Polymers, vol. 113, pp. 561-568, 2014.

[39] M. Pluta, A. Galeski, M. Alexandre, M.-A. Paul, and P. Dubois, "Polylactide/montmorillonite nanocomposites and microcomposites prepared by melt blending: structure and some physical properties," Journal of Applied Polymer Science, vol. 86, no. 6, pp. 1497-1506, 2002.

[40] M. Dionísio, M. T. Viciosa, Y. Wang, and J. F. Mano, "Glass transition dynamics of poly(L-lactic acid) during isothermal crystallisation monitored by real-time dielectric relaxation spectroscopy measurements," Macromolecular Rapid Communications, vol. 26, no. 17, pp. 1423-1427, 2005.

[41] Y. Wang, J. L. G. Ribelles, M. S. Sánchez, and J. F. Mano, "Morphological contributions to glass transition in poly $(\mathrm{L}-$ lactic acid)," Macromolecules, vol. 38, no. 11, pp. 4712-4718, 2005.

[42] J. F. Mano, J. L. Gómez Ribelles, N. M. Alves, and M. Salmerón Sanchez, "Glass transition dynamics and structural relaxation of PLLA studied by DSC: influence of crystallinity," Polymer, vol. 46, no. 19, pp. 8258-8265, 2005.

[43] A. Balogh, G. Drávavölgyi, K. Faragó et al., "Plasticized drugloaded melt electrospun polymer mats: characterization, thermal degradation, and release kinetics," Journal of Pharmaceutical Sciences, vol. 103, no. 4, pp. 1278-1287, 2014.

[44] J. S. Choi and W. H. Park, “Thermal and mechanical properties of poly(3-hydroxybutyrate-co-3-hydroxyvalerate) plasticized by biodegradable soybean oils," Macromolecular Symposia, vol. 197, no. 1, pp. 65-76, 2003.

[45] G. Adam and J. H. Gibbs, "On the temperature dependence of cooperative relaxation properties in glass-forming liquids," The Journal of Chemical Physics, vol. 43, no. 1, pp. 139-146, 1965.

[46] J. Oliveira, G. S. Brichi, and J. M. Marconcini, "Effect of solvent on the physical and morphological properties of poly(lactic acid) nanofibers obtained by solution blow spinning," Journal of Engineered Fibers and Fabrics, vol. 9, no. 4, 2014. 

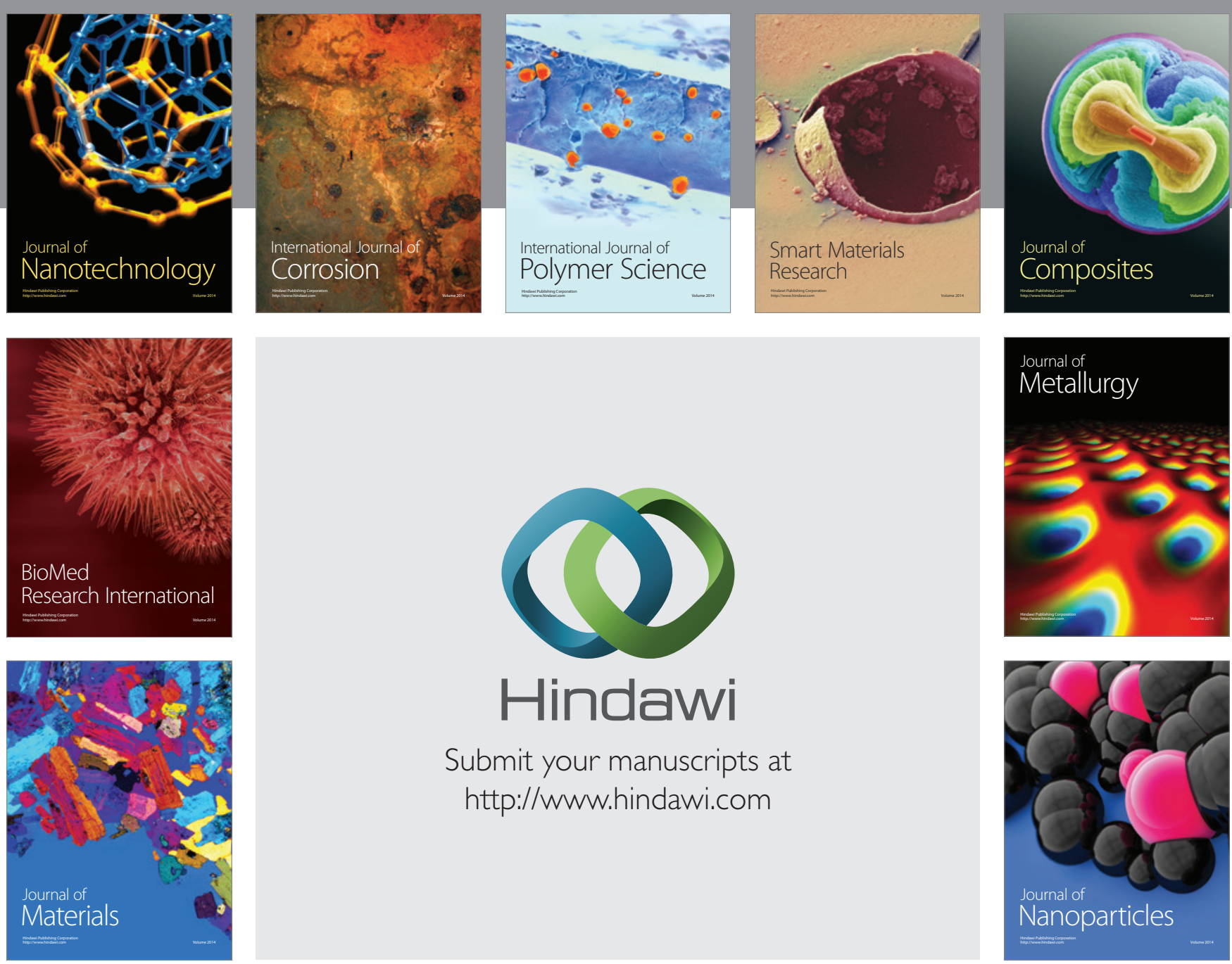

Submit your manuscripts at http://www.hindawi.com
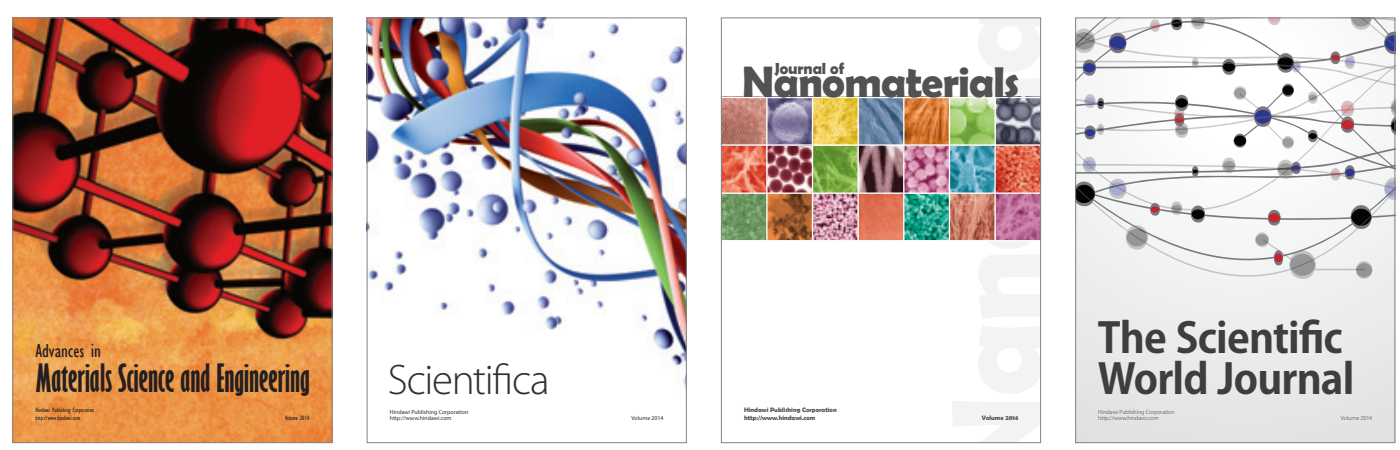

\section{The Scientific World Journal}
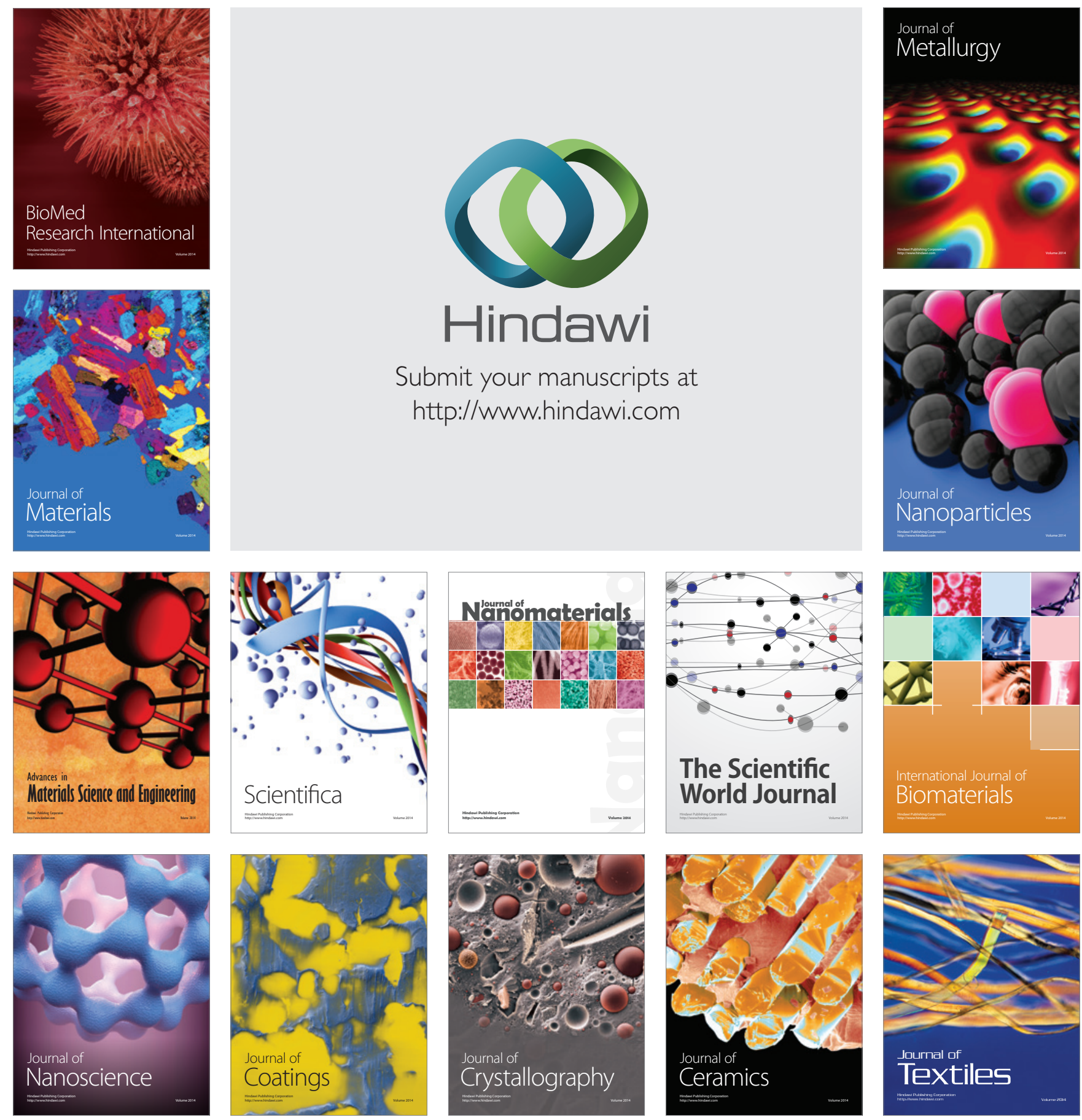